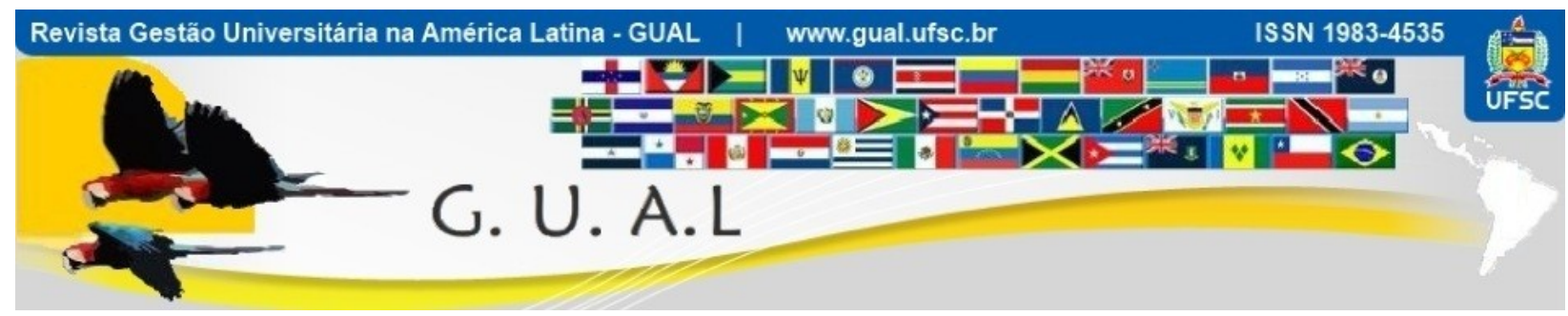

DOI: http://dx.doi.org/10.5007/1983-4535.2013v6n1p22

\title{
A TRAJETÓRIA E A FUNCIONALIDADE DA UNIVERSIDADE PÚBLICA BRASILEIRA
}

\section{THE TRAJECTORY AND THE FUNCTIONALITY OF BRAZILIAN PUBLIC UNIVERSITY}

Júnia Maria Zandonade Falqueto, Especialista Universidade de Brasília - UnB jufalqueto@gmail.com

Josivania Silva Farias, Doutora Universidade de Brasília - UnB josivania@gmail.com

Recebido em 30/agosto/2012

Aprovado em 28/novembro/2012

Sistema de Avaliação: Double Blind Review

Esta obra está sob uma Licença Creative Commons Atribuição-Uso. 


\begin{abstract}
RESUMO
Este trabalho propõe uma reflexão sobre o modelo de gestão das universidades federais brasileiras. O objetivo principal é analisar a influência de dois importantes modelos de gestão pública (a burocracia e o gerencialismo) na gestão universitária do País. Inicialmente, discutese a trajetória da universidade na América Latina, enfatizando o histórico brasileiro. Em seguida, analisa-se a influência do modelo burocrático. Por fim, delineia-se a lógica gerencial na gestão da educação superior brasileira, admitindo se tratar de um novo paradigma à gestão universitária. Parte-se de um aparato teórico que subsidia o desenvolvimento da discussão acerca da trajetória e da funcionalidade dessas instituições. Os resultados evidenciaram que as universidades brasileiras são geridas a partir de estruturas burocráticas, ocasionando um cenário de conflitos na tomada de decisão e de pouca eficiência, embora já se verifique, na literatura e também no cotidiano dessas organizações, o discurso gerencialista, que pressupõe o ajuste das universidades à lógica de gestão do setor privado. Não se defende aqui que universidades públicas devam ser desvirtuadas para a lógica privatizadora do bem público e gratuito, tampouco percam sua autonomia. Porém, seria salutar repensar o combate às características prejudiciais à sua gestão: o corporativismo, o excesso de regras e a rigidez.
\end{abstract}

Palavras-chave: Universidade Pública. Burocracia. Gerencialismo.

\begin{abstract}
This paper aims at a reflection on the management model of the Brazilian federal universities. The main objective is to analyze the influence of two important models of public administration (bureaucracy and managerialism) on university management in the country. Initially, the history of the university in Latin America is brought under appreciation, emphasizing the history of Brazil. Next the influence of the bureaucratic model will come under close scrutiny. Finally, this paper addresses the managerial logic as regards Brazilian higher education, assuming it is a new paradigm to the university management. It starts with a theoretical apparatus that subsidizes the development of critical thinking about the trajectory and functionality of these institutions. The results show that Brazilian universities are managed from bureaucratic structures, leading to a scenario which proves low-achieving and conducive to conflicts in decision making, although the literature and the daily life of these organizations alike already mirror the managerialist discourse which assumes the adjustment of universities to the logic of management as viewed in the private sector. There is no advocating here that public universities should be veered into the privatization-minded logic of the public, good and free, nor deprived of their autonomy. However, it might prove salutary to rethink the struggle against such characteristics harmful to the management of them as corporatism, the excess of rules and rigidity.
\end{abstract}

Keywords: Public University. Bureaucracy. Managerialism. 


\section{INTRODUÇÃO}

O debate sobre as temáticas educacionais tem evidenciado que se faz urgente ampliar a oferta de educação superior nos países em desenvolvimento, sob pena de tornar-se cada vez mais difícil a esses países tomarem parte na economia mundial desenvolvida com base no conhecimento (MARTINS, 2003; CABRAL NETO; RODRIGUEZ, 2007, BARBALHO, 2007).

A educação é instrumento de garantia de maior equidade pressupondo-se que uma sociedade poderá ser mais justa e democrática se estiver fundamentada em educação de qualidade para todos. Nesta perspectiva, pode ser percebido como é paradoxal o fato de a educação superior não ter acompanhado o processo de transformações sociopolíticas e econômicas que exigem, entre outras demandas, mudanças em sua forma de gestão. (BARBALHO, 2007).

As universidades federais brasileiras, da forma como são estruturadas, se tornaram instituições retardatárias em relação aos avanços em políticas de ensino, sistemas organizacionais, estratégias de ação e flexibilidade. Uma situação que chama atenção é a resistência dessas instituições à mudança. Mesmo sendo um consenso o fato de que a melhoria do ensino superior é fundamental para o desenvolvimento do País, a universidade brasileira enfrenta muitas dificuldades para implementar reformas e mudanças significativas (CHAUÍ, 2003; VIERA, VIEIRA;2004; BARBALHO,2007).

Protelar a mudança e a adoção de inovações nas universidades federais é o mesmo que empurrá-las para o passado, perenizando-as em um contexto cada vez mais distante dos padrões de funcionalidade que lhes garantam a legitimidade, identificações capazes de justificá-las como públicas, gratuitas e de qualidade perante a sociedade que, afinal, as mantém (VIEIRA; VIEIRA, 2004).

O principal objetivo deste trabalho é discutir a influência da burocracia e do gerencialismo na trajetória e na funcionalidade das universidades federais brasileiras.Para isto, o estudo está dividido em três partes. Na primeira, apresenta-se a trajetória da universidade a partir de sua institucionalização na América Latina. Desenvolve-se um breve relato sobre suas características, sobretudo estruturais, para em seguida tratar de aspectos específicos da formação e do desenvolvimento da universidade no Brasil. Na segunda parte, é apresentada uma abordagem analítica, concentrada nos aspectos burocráticos da funcionalidade das universidades. Por fim, discute-se a gestão da educação superior embasada 
no modelo gerencial. Abordando, principalmente, as tendências da gestão educacional das universidades federais quando incorporada a lógica gerencial.

\section{A UNIVERSIDADE NA AMÉRICA LATINA}

Durante muito tempo a universidade reagiu ou obedeceu às premências de seu contexto histórico. Para conformar-se às necessidades da Revolução Francesa tornou-se profissionalizante. Para responder às exigências do desenvolvimento científico da Prússia, tornou-se universidade de pesquisa. Para corresponder à necessidade de democratização do acesso à educação em países em desenvolvimento ao final do século XIX e início do século XX, tornou-se universidade de massas, adotando múltiplos modelos (SGUISSARD, 2004).

Na América Latina, conforme afirma Ribeiro (1978), o modelo inspirador foi o padrão francês de universidade, no qual a estrutura se assemelha a um aglomerado de escolas autárquicas. Porém, não se deve afirmar que o modelo francês foi adotado em sua totalidade. O que caracterizava o sistema educacional da França imperial era seu conteúdo político de instituição centralizadora, de órgão monopolizador da educação geral destinado a desfeudalizar e unificar culturalmente a França (RIBEIRO, 1978).

Entretanto, os valores políticos franceses não foram herdados pelas universidades latino-americanas (SGUISSARD, 2004). Estas buscaram, principalmente, receber a postura universitária fomentadora de escolas autárquicas, o profissionalismo e a introdução do culto positivista nas novas instituições reguladoras do regime capitalista.

Dessa forma, construídas conforme o modelo positivista francês, pode-se afirmar que as universidades latino-americanas são conglomerados de faculdades e escolas que idealmente deveriam cobrir todas as linhas da formação profissional, por meio de correspondente número de unidades acadêmicas independentes e autossuficientes (RIBEIRO, 1978; SGUISSARD, 2004).

Por outro lado, apesar de inserida no contexto latino-americano, a trajetória brasileira merece ser analisada de forma separada devido às particularidades que apresenta quando comparada às nações colonizadas por ingleses e espanhóis (TEIXEIRA, 1999; FÁVERO, 2006; SGUISSARD, 2006).

O Brasil constitui uma exceção na América Latina. Tentativas sem êxito de criação de uma universidade ocorreram por mais de um século, como o esforço malsucedido da Câmara da Bahia, em 1671, e o que constava da agenda da Inconfidência Mineira, em 1789. O 
surgimento do ensino superior representou um acontecimento tardio na sociedade brasileira (AZEVEDO, 1971; TEIXEIRA, 1999; FÁVERO, 2006; MARTINS, 2003).

Segundo Buarque (2003), a primeira grande instituição de ensino superior no país, a Universidade de São Paulo, surgiu somente em 1934. Sem estar vinculada a ideais religiosos, monárquicos ou à submissão a políticos brasileiros, a Universidade de São Paulo foi o resultado da articulação entre intelectuais brasileiros e franceses. A partir desse período, o Brasil passou a olhar para dentro e não mais para fora. Posturas servis foram perdendo espaço para a intelectualidade acadêmica, embora ainda existisse forte dependência do exterior. A partir daí, deflagraram-se momentos importantes na trajetória da educação superior brasileira.

No período de trinta anos, compreendido entre 1930 e 1964, foram criadas mais de vinte universidades federais no Brasil. O surgimento de tantas universidades públicas marcou a expansão do sistema público federal de educação superior (PANIZZI, 2004).

Neste período, a universidade foi paradoxalmente destruída e fundada (BUARQUE, 2003). Destruída pela aposentadoria forçada de centenas de professores, exilados ou expulsos pela ditadura recém-instalada a partir de 1964, que pôs fim também à liberdade de cátedra. Ao mesmo tempo, ela foi fundada em uma estrutura mais moderna e, pela primeira vez, tentou-se criar um sistema universitário nacionalmente integrado. Passou a existir maior disponibilidade de recursos e apoio à modernização da universidade brasileira. E, o mais importante, iniciouse a concessão de bolsas de estudos no exterior para onde jovens brasileiros foram enviados para cursar doutorado e mestrado em universidades estrangeiras (ROMANO, 2006; BUARQUE, 2003).

Em 1968, teve início uma nova fase da educação superior brasileira com o movimento da reforma universitária, que tinha como diretrizes a eficiência administrativa, a estrutura departamental e a indissociabilidade do ensino, pesquisa e extensão como lema das Instituições de Ensino Superior. O contexto, na década de 70, impulsionou o desenvolvimento de cursos de pós-graduação no Brasil e ampliou as possibilidades de realização de cursos de pós-graduação no exterior, com vistas à capacitação avançada do corpo docente brasileiro (PANIZZI, 2004; BUARQUE, 2003)

A partir de 1985, o fim do regime militar trouxe de volta o direito de escolha dos dirigentes universitários, com eleição direta para o cargo de reitor. Entretanto, trouxe também forte restrição de recursos financeiros (BUARQUE, 2003).

Nos anos seguintes, ocorreu o que Sguissard (2006) classifica como uma modernização conservadora, que se iniciou no governo de Collor de Mello (1990-1991), 
seguiu-se na gestão de Itamar Franco (1992-1994) e recrudesceu-se no governo FHC (19952002). Nesse período, sobretudo no Governo FHC, efetivou-se uma série de ajustes estruturais e fiscais, e reformas orientadas para o mercado, com um foco gerencial, objeto a ser tratado com maior detalhamento mais adiante. Neste período, ocorreram as principais medidas conducentes à reconfiguração dos setores público e privado, no âmbito do Estado, assim como da educação superior.

Em seguida, inicia-se a análise da influência de dois importantes modelos de gestão pública (modelo burocrático e gerencial) na trajetória e na funcionalidade das universidades brasileiras.

\section{O MODELO BUROCRÁTICO E A UNIVERSIDADE}

Verifica-se na literatura (eg. BLAU, 1984; VIEIRA, VIEIRA, 2004; CASTRO, 2007), que a gestão instituída nas universidades públicas brasileiras possui muitas características burocráticas. Para Weber (1999), a burocracia é um padrão eficiente da administração, uma forma racional de poder.

É a forma mais racional de dominação, porque nela se alcança tecnicamente o máximo de rendimento em virtude de precisão, continuidade, disciplina, rigor e confiabilidade, intensidade, extensibilidade dos serviços, e aplicabilidade formalmente universal a todas as espécies de tarefas (WEBER, 1999, p.145).

A teoria da burocracia está concentrada nos conceitos de produtividade, eficiência e estrutura organizacional. O estudo das organizações e as relações de poder, autoridade e legitimidade que acontecem no interior das organizações constituíram parte central da teoria da de Weber, na qual a burocracia implica, necessariamente, em um sistema consistente de normas e regulamentos, em hierarquia e controle organizacional (CASTRO, 2007). Segundo Lima (2001), a burocracia constitui a forma mais racional de administrar, aquela que afasta erros, afetos e sentimentos e, em corroboração ao pensamento de Weber, é capaz de atingir o mais alto grau de eficiência.

Entretanto, a compreensão de Max Weber sobre a burocracia e seus efeitos é, muitas vezes, antagônica àquela descrita por outros autores e pelo senso comum.

No Brasil, a administração pública burocrática veio substituir as formas patrimonialistas de gestão e ganhou importância em função da necessidade de maior previsibilidade e precisão no tratamento das questões organizacionais. Apresentou-se como 
reação ao nepotismo e ao subjetivismo, que tiveram lugar nos primeiros anos da Revolução Industrial (BRESSER-PEREIRA, 1998).

Com o tempo e devido aos resultados apresentados, sobretudo em relação à administração pública brasileira, o modelo burocrático tornou-se alvo de ásperas críticas. A burocracia foi considerada inadequada para o contexto institucional contemporâneo por sua presumida ineficiência, morosidade, estilo autorreferencial, e distanciamento das necessidades dos cidadãos (BARZELAY, 1992; OSBORNE, GAEBLER; 1992).

São muitos os questionamentos feitos ao modelo burocrático, tal como caracterizado por Weber, seja porque apresenta disfunções (MERTON, 1965), seja porque se supõe que os burocratas agem na defesa dos próprios interesses (DOWNS, 1994); seja porque preza por um formalismo exagerado (CAMPOS, 1976). Estes questionamentos problematizam a noção de que a burocracia do setor público constitui um mecanismo de governo neutro, direto, eficiente e inequívoco. O 'ótimo' de eficiência do tipo ideal de burocracia parece não se verificar na prática.

Particularizando para o caso das instituições federais de ensino superior brasileiras, estas se tornaram "instituições burocráticas recalcitrantes à mudança e rarefeitas à inovação" (VIERA; VIEIRA, 2004, p.1). A forma de comportamento dos atores envolvidos na dinâmica administrativa e acadêmica das universidades públicas brasileiras se reporta, em grande parte, às competências distribuídas e amparadas no sistema normativo instituído (VIEIRA; VIEIRA, 2004).

Nas organizações públicas, a exemplo das universidades federais, enfrentam-se dificuldades para abandonar características burocráticas não desejáveis, tais como o corporativismo e o excesso de regras. As dimensões da atividade acadêmica universitária ensino, pesquisa e extensão - se tornam, ocasionalmente, reféns de um processo burocrático amplo, submetido a normas e dependências às vezes desnecessárias, produzidas pelas estruturas piramidais de apoio (SANTIAGO, 2003; VIEIRA; VIEIRA, 2004).

Não é estranho que universidades estruturadas em centros, faculdades, institutos, programas, decanatos, colégios, comissões, coordenações, núcleos, fundações, secretarias e outras tantas formas funcionais possuam uma tendência natural de se constituir em organismos burocráticos de grande densidade. E, sendo assim, as tentativas de mudança na intenção de simplificar, agilizar e racionalizar tal estrutura burocrática complexa enfrentam resistências internas. 
A complexidade estrutural e organizacional das universidades federais gera distorções com a plena identidade das funções de ensino, pesquisa e extensão. A pesquisa e a extensão são, em alguns casos, apêndices da atividade de ensino e não funções programáticas com personalidade acadêmica própria, como deveriam ser. A atividade de pesquisa se desenvolve por ação complementar dos docentes, em ambientes de ensino e de caracterização muito individualizados. Os ambientes de pesquisa que apresentam nível elevado - de excelência nesta atividade ainda estão em número insuficiente.

E nesse sentido, a estrutura departamental pode ser negativa por alocar em um mesmo ambiente, e sem definições claras, as funções de ensino e pesquisa da universidade. O mesmo ocorre com a extensão, um campo de indefinição e pouca adequação de escopo, fazendo parte do conjunto comum de atividades departamentais. O caráter colegiado das decisões não neutraliza nem a natureza burocrática das competências legais, nem as formas de domínio hierárquico. Assim, é errônea a visão de que o modelo colegiado de tomada de decisão se opõe à forma burocrática de gestão, pelo contrário, os dois modelos interpenetram-se (SANTIAGO, 2003; VIEIRA; VIEIRA, 2004).

Outra questão é a forma como o poder se distribui nas universidades federais brasileiras. Lisboa (2004, p.136), referindo-se às universidades públicas, afirma que "nelas vige um sistema institucionalizado de poder que bloqueia a fermentação de ideias, pune os criativos e rebeldes, premiando apenas os amiguinhos do rei”. Para Vieira e Viera (2004), a distribuição de poder em estruturas complexas, entre elas, particularmente, as universidades, segue uma rede densamente ramificada, na qual se destacam pontos de maior ou menor concentração de força decisória. Os baixos limites decisórios da autoridade burocrática fazem com que o poder de decisão, mesmo que individualizado ou colegiado, esteja muito distante do ambiente que gerou a demanda.

De acordo com Silva (2004), é na formulação das estratégias que melhor se pode compreender a disseminação do poder nas universidades. A base de poder é muito alargada, pois, nas questões essenciais de decisão, são envolvidas inúmeras pessoas, não só aqueles que detêm cargos oficiais, mas, também, muitos docentes. Segundo este autor, cada docente tem grande autonomia no desenvolvimento do seu trabalho profissional podendo gerar a sua própria estratégia no processo de ensino e ir adaptando-a em função dos seus objetivos.

Ainda nesta linha, Vieira e Vieira (2004, p.189) reconhecem que a disfunção do poder ocorre de forma predominante nas complexas estruturas organizacionais. Essa disfunção seria 
a "consequência do excesso divisional da estrutura, da multiunivocidade e de poderes paralelos que emergem no interior da organização".

No caso das universidades, a funcionalidade burocrática produz baixa energia sistêmica comprometendo a qualidade dos procedimentos e a possibilidade de introdução de uma nova racionalidade, uma vez que as decisões - pessoais ou colegiadas - se movimentam demasiadamente pelas teias hierarquizadas da burocracia. Assim, a distribuição do poder, em grande parte das instituições públicas de ensino superior brasileiras, tende a seguir uma rede ramificada, na qual se destacam pontos de maior ou menor concentração de força decisória. Trata-se de uma distribuição desigual do poder, na qual poucos podem muito e muito quase não tem voz (VIEIRA; VIEIRA, 2004).

O corporativismo é também considerado uma disfunção do poder à medida que impõe posições, estabelece enfrentamentos e cria um corpo de resistência dentro de um sistema burocrático. Segundo Viera e Vieira (2004), esta é a forma mais aguda do poder. A defesa de interesses de uma minoria, que age como se representasse os interesses de uma coletividade, se manifesta mais intensamente nas estruturas estanques, do tipo departamental, facilmente encontradas nas estruturas universitárias, onde é comum interesses grupais e pessoais sobrepujarem aos institucionais (SILVA, 2004;VIEIRA; VIEIRA, 2004).

Por fim, admite-se que a análise da funcionalidade burocrática das universidades federais fomenta o debate sobre questões da atualidade, sem as quais não seria possível equacionar melhorias ao sistema educacional brasileiro.

Vieira e Viera (2004) defendem que a mobilização das comunidades universitárias em direção às mudanças estruturais, organizacionais, acadêmicas e, principalmente, de comportamento (passando de uma cultura burocrática a outra pós-burocrática) é o grande passo no caminho da reestruturação necessária. Para tanto, sugerem uma tomada de decisão conjunta entre universidades federais e o Ministério da Educação, no sentido de subsidiar a mudança. Tal processo deverá partir de um pressuposto básico: simplificar e estabelecer uma nova ordem funcional, mais flexível, mais ágil, menos corporativista.

\section{O MODELO GERENCIAL E A UNIVERSIDADE}

A transição da administração burocrática para a gerencial ocorre a partir de $1980 \mathrm{em}$ resposta à necessidade de maior eficiência nos serviços sociais e científicos que o Estado passou a realizar, conforme descreve Bresser-Pereira (1998): 
Após a II Guerra Mundial há uma reafirmação dos valores burocráticos, mas, ao mesmo tempo, a influência da administração de empresas começa a se fazer sentir na administração pública. As ideias de descentralização e de flexibilização administrativa ganham espaço em todos os governos. Entretanto, a reforma da administração pública só ganhará força a partir dos anos 70 , quando tem início a crise do Estado, que levará também à crise sua burocracia. Em consequência, nos anos de 1980 inicia-se uma grande revolução na administração pública dos países centrais em direção a uma administração pública gerencial (BRESSER-PEREIRA, 1998, p. 242)

O Estado gerencial pressupõe uma administração democrática e plural, que busca desburocratizar a estrutura administrativa e moldar as organizações públicas aos seus objetivos prioritários - os resultados - aceitando, dessa forma, uma maior participação dos agentes privados e das organizações da sociedade civil (BRESSER-PEREIRA, 1997)

Bresser-Pereira (1998) identifica no modelo gerencial a descentralização do ponto de vista político e administrativo, a diminuição de níveis hierárquicos, o aumento da autonomia de gestores públicos, os pressupostos da confiança limitada e não da desconfiança total, o controle por resultado (a posteriori) - ao invés do controle rígido - e, por fim, a administração voltada para o atendimento do cidadão, em vez de autorreferida.

O gerencialismo influenciou e continua a influenciar reformas administrativas em diversos países, redirecionando as formas de intervenção do Estado e da gestão das políticas públicas. Assim, ao importar princípios e práticas da gestão empresarial, o Estado tem redefinido o conceito de gestão pública, com implicações na gestão educacional (CARVALHO, 2009).

O novo conceito do Estado Gerencial envolve uma modificação do modelo burocrático weberiano em prol de organizações mais flexíveis, da administração descentralizada, autônoma e participativa e da redefinição das relações entre domínios públicos e privados.

Sennett (2000) identifica três aspectos estruturais e organizacionais na moderna forma de flexibilidade dos processos de trabalho na abordagem gerencialista: a especialização flexível da produção, a reinvenção descontínua das instituições e a concentração do poder sem centralização. Para efeito do presente ensaio, interessa, sobretudo, as duas últimas características citadas.

A prática administrativa moderna é pautada em redes mais abertas à reinvenção das hierarquias piramidais, isto é, substituem-se as hierarquias verticais, rígidas e claramente definidas por redes mais frouxas (SENNETT, 2000). O gerenciamento descentralizado implica no desaparecimento do supervisor; permite que os trabalhadores tenham maior 
controle sobre suas atividades e tende a adotar modelos de organização cooperativa e discursiva, em cujas tomadas de decisão os trabalhadores são envolvidos. O autor conclui que a tecnologia aliada à flexibilização vem desmantelando as antigas estruturas burocráticas de poder e que o novo princípio fundamental pode ser o da autorregulação. Assim, ao trabalhador é atribuída maior responsabilidade pela sua própria eficiência, produtividade ou permanência no trabalho. A internalização do controle é combinada com a responsabilização do grupo pela consecução das metas na célula da produção.

A terceira característica da forma de flexibilidade dos processos de trabalho na abordagem gerencialista, conforme Sennett (2000) é a concentração de poder sem centralização. Isto é, os aspectos que se mostraram ineficientes na gestão burocrática impõem a necessidade de uma nova forma de administração. A autoridade burocrática é substituída pela autonomia democrática, cujo gestor não mais centraliza o poder, mas coordena e agiliza a tomada de decisões por parte das equipes de trabalho. Desta forma, a flexibilização na gestão permite uma 'concentração democrática' do poder, podendo-se prescindir da centralização.

Portanto, a flexibilização expressa uma mudança na forma do trabalho. A racionalidade técnica, burocrática e normativa é substituída por competências de interação e responsabilidade pessoal, que tornam o trabalho mais funcional, ajustando-o às incessantes mudanças de uma sociedade cada vez mais exigente e atuante.

O trabalho em grupo, a cooperação, a participação, a autonomia e a gestão descentralizada, segundo Carvalho (2009), tornaram-se aspectos relevantes para a prática administrativa moderna. Para a autora, isto muda radicalmente a estrutura de poder dentro da organização: desaparece a autoridade centralizada, dando lugar ao "exercício flexível de poder, ou seja, à horizontalidade do poder de decisão e à atribuição de cargos mais fluida" (CARVALHO, 2009, p. 1143). Estas novas características da gestão não significam apenas novas formas de gerenciar as organizações, pois também revelam que:

\footnotetext{
As novas formas de os homens se pensarem e se organizarem socialmente condicionam as demais formas de organização política e social da atualidade e compelem os indivíduos a buscar autonomia pessoal diante das estruturas coletivas, baseadas no valor normativo das tradições ou do poder do Estado, e a se desvincular das lealdades institucionais (CARVALHO, 2009, p.1144)
}

Para esta autora, é inerente a esse processo de reestruturação produtiva um movimento de reinvenção dos poderes e das funções do Estado, cujas repercussões abrangem o campo educacional. Cabe, assim, discutir aspectos que caracterizam a tendência da atuação estatal. 
No Brasil, o projeto de reforma gerencial do Estado, substanciado no Plano Diretor da Reforma do Aparelho do Estado (1995), abriu espaço para mudanças organizacionais e administrativas que repercutiram substancialmente na educação.

De acordo com os pressupostos do modelo gerencial, o Estado deixa de ser investidor e mantenedor, eximindo-se da responsabilidade direta de produzir e fornecer bens ou serviços e assumindo o papel de regulador e facilitador da iniciativa privada (BRESSER-PEREIRA, 1998). Sua intervenção consiste em redistribuir ou realocar recursos, em introduzir regras orientadoras das relações entre os prestadores públicos e privados, em avaliar previamente necessidades e recursos disponíveis, em definir antecipadamente metas e posteriormente monitorar sua realização. Separa-se, assim, a função de governar e a de executar. Tal separação permite que o Estado faça concessão de serviços, introduzindo mecanismos externos de contratação, transferindo para as instituições privada ou pública - não estatal (na qualidade de prestadoras) funções e serviços que tradicionalmente eram desempenhados pelo governo. Busca-se uma administração pública descentralizada, mais eficiente e voltada para o atendimento dos cidadãos (BRESSER-PEREIRA, 1998; CARVALHO, 2009).

Restringir o Estado à função de regulação e de catalisação implica, na visão de Carvalho (2009), aumentar a participação social em atividades que antes eram exclusivas. Para tanto, torna-se necessário estimular continuamente a busca de soluções fora do setor público, por meio de agências autônomas ou organizações sociais, da cooperação voluntária da comunidade e da co-parceria com a iniciativa privada na consecução de serviços de interesse público, introduzindo-se, ao mesmo tempo, uma nova proposta de regulação social, sustentada na participação.

De acordo com o Plano Diretor da Reforma do Aparelho do Estado (1995), as Universidades são classificadas como serviço não-exclusivo do Estado. Bresser-Pereira (1998) apresenta a seguinte definição:

\footnotetext{
Os serviços não-exclusivos ou competitivos são aqueles que, embora não envolvendo poder de Estado, o Estado realiza e/ou subsidia porque os considera de alta relevância para os direitos humanos, ou porque envolvem economias externas, não podendo ser adequadamente recompensados no mercado através da cobrança dos serviços (BRESSER-PEREIRA, 1998, p.258)
}

São exemplos deste setor, além das universidades, os museus, os centros de pesquisa e os hospitais.

A propriedade (dos serviços e das organizações), no setor de serviços não-exclusivos, deve ser, em princípio, pública não-estatal. Não-estatal porque não envolve o uso do poder de 
Estado. Não cabe ser privada porque pressupõe transferências de recursos públicos e deve ser pública para justificar subsídios recebidos do governo. O fato de ser pública e não estatal, por sua vez, implicará na necessidade de a atividade ser controlada de forma mista - pelo mercado e pelo Estado. O controle do Estado, entretanto, será necessariamente antecedido e complementado pelo controle social direto. Já o controle do mercado se materializará na cobrança dos serviços. Desta forma, a sociedade estará continuamente atestando a validade dos serviços prestados, ao mesmo tempo em que se estabelecerá um sistema de parceria (ou de cogestão) entre Estado e sociedade civil (BRESSER-PEREIRA, 1998).

Para Carvalho (2009), no modelo gerencial de administração pública, o governo financia os resultados e não apenas concede recursos. Nesta perspectiva, os governos devem adotar mecanismos de avaliação e de aferição de resultado que, por meio de um ranking, classifiquem e tornem públicos os efeitos.

Sobre a necessidade de avaliação, Buarque (2003) afirma que a reorganização das universidades necessitará da formulação de novos mecanismos de controle e aferição, que permitam muito mais do que classificá-las. O objetivo de novos mecanismos deverá ser o de identificar a realidade das universidades, suas qualidades e pontos fortes, a fim de capacitá-las a desempenhar o papel que a sociedade espera.

A avaliação não objetivaria somente o controle de resultados por parte do Estado, por meio do "estabelecimento de parâmetros para a comparação e classificação dos desempenhos, estímulo por meio de premiação, possibilidade de controle público do desempenho do sistema escolar" (SOUZA; OLIVEIRA, 2003, p. 881 apud CARVALHO, 2009). Seria também um mecanismo para induzir à prestação de contas e à responsabilização pelos resultados alcançados, ou seja, um mecanismo para informar sobre a eficiência e produtividade dos serviços educacionais.

$\mathrm{Na}$ perspectiva gerencial, os governos devem recorrer mais a incentivos e menos à imposição de regras e regulamentos. Assim, a avaliação representa um importante instrumento de controle, regulação e fiscalização. Ou seja, por meio da avaliação é possível esclarecer os cidadãos usuários dos serviços, quanto ao desempenho das universidades e, ao mesmo tempo, medir os resultados dos investimentos em educação, levantando indicadores para o repasse de verbas públicas, quando for o caso.

Uma forma de acompanhamento e supervisão do Estado na educação superior tem sido o ENADE - Exame Nacional de Desempenho dos Estudantes. Entretanto, trata-se de uma ferramenta que avalia apenas o ensino de graduação. É por meio do ENADE que o 
rendimento dos alunos de graduação, ingressantes e concluintes, é avaliado em relação aos conteúdos programáticos dos cursos em que estão matriculados (INEP, 2011). O exame é obrigatório e condição indispensável para a emissão do histórico escolar, assim como para a expedição do diploma. A primeira aplicação deste exame ocorreu em 2004 e a periodicidade máxima com que cada área do conhecimento é avaliada é trienal.

Segundo Carvalho (2009), a relação existente entre o modelo gerencial e a gestão da educação aparece também nos sistemas de controle criados pelo Estado. Atuando como regulador, o Estado recorre a empresas, agências de regulação e até mesmo ao próprio consumidor ou cidadão usuário dos serviços, passa a ser considerado como um juiz na avaliação da qualidade dos serviços públicos, favorecendo a comparação de resultados e induzindo a concorrência entre as empresas públicas e privadas.

O interesse em aumentar o poder do cidadão-consumidor também é encontrado no Plano Diretor (1995, p.40):

A modernização do aparelho do Estado exige, também, a criação de mecanismos que viabilizem a integração dos cidadãos no processo de definição, implementação e avaliação da ação pública. Através do controle social crescente será possível garantir serviços de qualidade.

Carvalho (2009) afirma que o gerencialismo, no campo educacional, se caracteriza por novas formas e combinações de financiamento, fornecimento, regulação e controle. A participação corresponde aos novos processos de regulação, cujas bases são as formas indiretas de controle, as novas condições de exercício do poder e a reconfiguração dos papéis nas várias instâncias do sistema educativo. No modelo gerencial, abre-se mão da regulação e do controle dos meios e procedimentos a priori em prol de uma regulação mais sistêmica e autônoma. É o caso da avaliação, que ao analisar os resultados e o desempenho dos alunos e não dos processos, reduz a interferência do Estado, o que não significa maior autonomia, mas um controle sem comandos explícitos.

Uma alternativa às universidades, visando maior eficiência, melhores resultados e menor custo, é a utilização do contrato de gestão, apesar de ser uma visão polêmica e não consolidada no País. Essa é a proposta defendida pelo modelo gerencial. A ideia é transformar as instituições publicas de ensino superior em organizações sociais, ou seja, em entidades que celebrem um contrato de gestão com o Poder Executivo e contem com autorização do Congresso Nacional para participar do orçamento público (BRESSER-PEREIRA, 1998). 
Por fim, há duas importantes formas de gestão introduzidas pelo modelo gerencial que poderão influenciar diretamente a gestão educacional, atingindo, sobretudo, as universidades federais. A primeira delas é a gestão por projetos, apresentada como forma de se eliminar custos desnecessários, desenvolver produtos e serviços correspondentes às inovações, às novas exigências dos diferentes públicos e à vantagem competitiva, além de criar uma estrutura organizacional mais flexível e integradora e maior cooperação entre pessoas, equipes e departamentos. Este modelo, seguindo a adhocacia operacional (sistema que preza pela simplificação dos processos burocráticos, pelas estruturas mais fluidas e pela horizontalidade do poder de decisão), baseia-se na substituição de regras formais e instrumentos regulares de execução do trabalho por uma forma de gestão flexível, dirigida para a realização de objetivos. Neste caso, os atores organizacionais, diretamente empenhados na realização do projeto, deverão contar com um clima organizacional dinâmico e cooperativo que favoreça a participação ativa e a tomada de decisão (CARVALHO, 2009).

Aplicado ao campo de gestão das universidades, o sistema de gestão por projetos, a exemplo do projeto político-pedagógico, envolve a identificação da missão, dos objetivos, das metas e estratégias, de forma a tornar possível a responsabilização coletiva ou individual pela realização das atividades, pelo controle operacional e monitoramento dos resultados.

A segunda forma de gestão introduzida pelo modelo gerencial é a gestão autônoma do sistema educacional. Trata-se de uma tentativa de promover a formação de uma identidade institucional e, ao mesmo tempo, o respeito à diversidade de interesses. Nesse sentido, a autonomia legitima a flexibilização organizacional (CARVALHO, 2009). Como se pode observar a Lei de Diretrizes e Bases (LDB) n. 9394/96, diferentemente das legislações anteriores, dá ênfase à descentralização, à autonomia das escolas e universidades, à participação da comunidade nos processos decisórios e flexibiliza a organização administrativa das instituições de ensino.

Pereira e Forte (2008, p.109) destacam as principais mudanças no ensino superior, promovidas a partir da LDB de 1996.

(...) autorização de cursos sequenciais; aceleração de estudos; inexistência de frequência mínima de alunos; liberdade de seleção de ingresso de alunos; abertura a instituições não-universitárias (centros universitários, faculdades integradas, faculdades, escolas superiores, institutos superiores e centros tecnológicos); existência de universidades especializadas por campo do saber; estímulo a investimentos da iniciativa privada; qualificação do corpo docente universitário (pelo menos um terço do corpo docente com titulação acadêmica de mestrado ou doutorado e um terço do corpo docente em regime de tempo integral); autonomia às universidades, com permissão para a criação, organização e extinção de seus cursos 
de graduação, fixação de currículos e número de vagas; conferência degraus, diplomas e outros títulos; criação de processo regular de avaliação do ensino pelo MEC/INEP (PEREIRA; FORTE, 2008, p. 109).

Os discursos gerencialistas consideram a universidade uma empresa como outras quaisquer (CARVALHO, 2009). Assim, enxergam a educação como um serviço que deve primar pela satisfação do cidadão enquanto cliente-consumidor, assegurando como critério de eficiência, seu direito à qualidade dos serviços prestados.

Por todo o exposto, faz-se necessário ressaltar que a reforma gerencialista do Estado submete as instituições públicas à lógica do mercado, admitindo os princípios da competição, da vantagem competitiva, da valorização do 'cliente-consumidor', da ênfase nos resultados, entre outros. Nesse processo, sugere-se que as Universidades se deixem guiar mais pelas demandas dos cidadãos-usuários do que por interesses coletivos. Tais mudanças impõem o desafio de aprofundar a compreensão desse processo e reavaliar o papel de determinados agentes de gestão das instituições de ensino superior.

\section{CONSIDERAÇÕES FINAIS}

O presente trabalho propôs a discussão da influência de dois modelos de gestão pública (o burocrático e o gerencialista) na trajetória e na funcionalidade da universidade federal brasileira, admitindo que a melhoria da gestão das universidades seja um desafio atual para o País.

Faz-se, inicialmente, uma reflexão sobre a trajetória da universidade na América Latina, a fim de se estudar a raiz da universidade brasileira e promover uma contextualização que permita ao leitor compreender a origem de características, sobretudo estruturais, da trajetória da gestão universitária no Brasil.

Importa destacar que a universidade latino-americana foi constituída conforme o modelo positivista francês subalternizado e, por essa razão, corresponde a um conglomerado de faculdades e escolas que, idealmente, deveria agrupar todas as possíveis linhas de formação profissional. Nesta estrutura universitária, as faculdades e departamentos são autossuficientes e a universidade, em si, é uma abstração institucional, concretizada nos atos de reitorias e nas reuniões de congregação (RIBEIRO, 1978).

Em seguida, apresenta-se um panorama da universidade brasileira, desde as primeiras tentativas de criação do ensino superior até o governo FHC (1995-2002), no qual o modelo gerencial é incorporado à gestão do país, com repercussões no setor educacional. Neste 
tópico, não há uma análise profunda em torno dos modelos de gestão pública. A principal intenção foi discutir a trajetória da universidade brasileira, passando por aspectos políticos e econômicos que a marcaram e, ainda hoje, fazem parte de sua complexidade.

Ao discutir a funcionalidade burocrática das universidades federais brasileiras, tem-se como principal referência a teoria weberiana. O modelo burocrático de Weber constitui um modelo de gestão racional. Lima (2001, p.121) ao descrevê-lo afirma que "afasta erros, afetos e sentimentos".

Do ponto de vista técnico, esse modelo é capaz de alcançar alto grau de eficiência, mas se perde em meio a possíveis distorções funcionais, como o excesso de normas, a rigidez e o corporativismo. Estas distorções se refletem em organismos burocráticos de grande densidade, o que dificulta o desempenho eficiente.

Discute-se neste trabalho que as universidades federais brasileiras são geridas a partir de estruturas organizacionais burocráticas devido, entre outras características, à sua multiciplicidade estrutural (faculdades, institutos, centros, programas, decanatos, colégios, comissões, coordenações, núcleos, fundações, secretarias e outros) ocasionando um cenário de conflitos na tomada de decisão, de baixas energia e sinergia funcionais e de uma burocratização pouco eficiente.

Em relação à diretriz gerencialista, trata-se de modificação estrutural do Estado e não deve ser confundida com simples implantação de novos padrões de gestão. Pelas possibilidades de participação, de autonomia, de flexibilização e de descentralização, o modelo gerencial se mostra útil ao aperfeiçoamento da gestão democrática, à medida que aperfeiçoa mecanismos de responsabilização, avaliação e transferência da administração pública (CASTRO, 2007).

O discurso gerencialista pressupõe o ajuste das universidades brasileiras à lógica do setor privado e, assim, propõe alterações em sua forma de gestão. Trata-se de modelo relativamente recente e a grande dificuldade de implantação ocorre em sua operacionalização, uma vez que as universidades federais são permeadas pelos entraves da cultura burocrática (CARVALHO, 2009).

Para finalizar, importa ressaltar que "a universidade não pode cumprir plenamente o seu papel se não está inteiramente sintonizada com o seu tempo e o futuro que ajuda a construir" (WERTHEIN, 2003, p.22). Devido à trajetória e às características burocráticas de sua funcionalidade, a universidade federal brasileira tende a ser conservadora. Sua mudança é processo delicado que não se cumpre por simples ato de vontade. É processo negociado, em 
face de divergências que enriquecem o debate. Porém, deve-se reafirmar que se a universidade pública brasileira não se ajustar às demandas contemporâneas dirigidas à gestão de organizações governamentais, tenderá a manter-se pouco eficiente, com consequências diretas na qualidade do ensino. (WERTHEIN, 2003).

Não se defende aqui que as universidades públicas brasileiras devam ser desvirtuadas para uma lógica privatizadora de gestão do bem público e gratuito, tampouco perder sua liberdade, entretanto, é necessário repensar sua gestão e combater características que prejudicam a sua dinâmica gerencial e a busca por resultados e eficiência. Alguns fatores prejudiciais são o corporativismo, o excesso de regras e a rigidez.

\section{REFERÊNCIAS}

AZEVEDO, F. A Cultura Brasileira. São Paulo: Melhoramentos. Editora da USP, 1971.

BARBALHO, M. A Educação Superior: Tendências e Estratégicas de Expansão na América Latina e no Brasil. In: CABRAL NETO, A. et al. (Org.). Pontos e Contrapontos da Política Educacional. Brasília: Líber Editora, 2007

BARZELAY, M. Breaking Through Bureaucracy: A New Vision for Managing in Government. Berkeley, CA: University of California Press, 1992

BLAU, P. M. Universidade como organização. Revista Brasileira de Administração da Educação. Porto Alegre, 1984, p. 10-26.

BRASIL. Lei n. 9.394 de 20 de dezembro de 1996. Estabelece as diretrizes e bases da educação nacional. Diario Oficial da União, Brasilía, ano cxxxiv, n. 1.248, 23 dez. 1996 p. 27833-27841.

BRASIL. Ministério da Administração Federal e da Reforma do Estado. Câmara de Reforma do Estado. Plano Diretor da Reforma do Aparelho do Estado. Brasília, DF: Presidência da República; Câmara de Reforma do Estado, 1995.

BRESSER-PEREIRA, L. C. Da Administração Pública Burocrática à Gerencial. In: BRESSER- PEREIRA, L.C.; SPINK, P. (Org.). Reforma do Estado e Administração Pública Gerencial. 2 ${ }^{\mathrm{a}}$ Ed. Rio de Janeiro: Editora Fundação Getulio Vargas, 1998, p.237-271

BRESSER-PEREIRA, Exposição no Senado sobre a Reforma da Administração Pública. Cadernos MARE da Reforma do Estado. Brasília, out.,1997. Disponível em: < http://www.planejamento.gov.br/secretarias/upload/Arquivos/publicacao/seges/PUB_Seges_ Mare_caderno03.PDF>. Acesso em 6 de julho de 2011.

BUARQUE, C.A Universidade numa Encruzilhada. In: A Universidade na Encruzilhada. Seminário Universidade: por que e como reformar? Brasilia, 6-7 ago. 2003. Brasília: UNESCO Brasil, Ministério da Educação, 2003. 
CABRAL NETO, A.; RODRIGUEZ. J. Reformas Educacionais na América Latina: cenários, proposições e resultado. In: CABRAL NETO, A. et al. (Org.). Pontos e Contrapontos da Política Educacional. Brasília: Líber Editora, 2007

CAMPOS, E. Sociologia da Burocracia. Rio de Janeiro: Zahar Editores, 1976.

CARVALHO, E. J. G. Reestruturação Produtiva, Reforma da Administração do Estado e Gestão da Educação. Educação e Sociedade, Campinas, Vol. 30, n. 109, p. 1139-1166, set./dez. 2009. Disponível em:

$<$ http://www.scielo.br/scielo.php?script=sci_arttext\&pid=S0101-

73302009000400011\&lang=pt>. Acesso em: 7 jul. 2011.

CASTRO, A. M. D.. Gerencialismo e Educação: Estratégias de Controle e Regulação de Gestão Escolar. In: NETO, A. C. et. al. (org.) Pontos e Contrapontos da Política Educacional, 1ª ed. Brasília: Líber Livro Editora, 2007.

CHAUÍ, M. A Universidade pública sob nova perspectiva. Revista Brasileira de Educação, São Paulo, n.24, p.5-15, set/out/Nov/Dez. 2003

DOWNS, E. Inside Burocracy. Boston: Little, Brown, 1994.

FAVERO, M. L. A. A Universidade no Brasil: das Origens à Reforma Universitária de 1968. Educar em Revista, Curitiba, n. 28, jul/dez. 2006. Disponível em:

$<$ http://www.scielo.br/scielo.php?script=sci_arttext\&pid=S010440602006000200003\&lang=p t>. Acesso em: 01 de julho de 2011.

INEP. Exame Nacional do Desempenho dos Estudantes. Disponível em: http://portal.mec.gov.br/index.php?Itemid=313\&id=181\&option=com_content\&view=article. Acesso em: 11 de Julho de 2011.

LIMA, B. D. La Nueva Gestíon Pública. Madrid: Pearson Educácion, 2001.

LISBOA, A. de M. O modo de produção de poder dentro da universidade. In: RAMPINELLI, W.J. O preço do voto: os bastidores de uma eleição para reitor. Florianópolis: Insular, 2004.

MARTINS, C. B. Reformar é preciso: Porém, em que direção? In: A Universidade na Encruzilhada. Seminário Universidade: por que e como reformar? Brasilia, 6-7 ago. 2003. Brasília: UNESCO Brasil, Ministério da Educação, 2003.

MERTON, R.K. Bureaucratic Structure and Personality. In: MERTON, R.K et al. Reader in Bureaucracy. New York: Free Press, 1965

OSBORNE, D.; GAEBLER, T. Reinventing Government: How the Entrepreneurial Spirit is Transforming the Public Sector. New York: Addison-Wesley Publishing Company, 1992 
PANIZZI, W. M. Pronunciamento II Reunião Plenária do Conselho Universitário IberoAmericano, Andifes, Brasília, 2004. Disponível em: http://www.cuib.org/cuib.pdf. Acesso em: 5 de julho de 2011.

PEREIRA, M. S.; FORTE, S. H. A. Visão Baseada em Recursos nas Instituições de Ensino Superior de Fortaleza: Uma Análise Ex-ante e Ex-Post à LDB/96. Revista de Administração Contemporânea, Curitiba , v.12. n.1. p-107-129 Jan./Mar. 2008

RIBEIRO, D. A Universidade Necessária. 3. ed. Rio de Janeiro: Editora Paz e Terra, 1978.

ROMANO, R. Reflexões sobre a Universidade. In: SILVA, M.; SILVA, R. (Org.). A Idéia de Universidade: Rumos e Desafios. Brasília: Líber Editora, 2006.

SENNET, R. A Corrosão do Caráter: Consequências Pessoais do Trabalho no Novo Capitalismo. $1^{\text {a }}$ Edição. Rio de Janiero: Record, 2000.

SANTIAGO, R. et al. Modelos de Governo, Gerencialismo e Avaliação Institucional nas Universidades. Revista Portuguesa de Educação, Braga, Portugal, Vol. 16, n. 1, pg 75-99, 2003.

SGUISSARD, V. et al. Universidade: Reforma e/ou Rendição ao Mercado?.Educação e Sociedade. Curitiba, Vol. 25, n. 88, p. 647-651, Out. 2004. Disponível em: http://www.scielo.br/scielo.php?pid=S0101-73302004000300001\&script=sci_arttext. Acesso em: 5 de julho de 2011.

SGUISSARD, V. Reforma Universitária no Brasil - 1995-2006: Precária Trajetória e Incerto Futuro. Educação e Sociedade . Curitiba, Vol. 27 n. 96 - Especial, p. 1021-1056, out. 2006. Disponível em: <http://www.scielo.br/pdf/es/v27n96/a18v2796.pdf >. Acesso em: 5 de julho de 2011.

SILVA, E. A. A. O Burocrático e o Político na Administração Universitária:

Continuidades e Rupturas na gestão dos recursos humanos na Universidade Agostino Neto (Angola). 2004. 528 fl. Tese (Doutorado em Educação)- Instituto de Educação e Psicologia, Universidade de Minho, Braga, 2004.

TEIXEIRA, A. Educação e Universidade. Rio de Janeiro: Editora UFRJ, 1999.

VIEIRA, E.; VIEIRA, M. Funcionalidade Burocrática nas Universidades Federais. Revista de Administração Contemporânea, Curitiba , v. 8. n.2. p-181-200 Abr./Jun. 2004

WEBER, M. Economia e sociedade: fundamentos da sociologia compreensiva, Vol. II Brasília: Editora da Universidade de Brasília, 1999.

WERTHEIN, J. Universidade: Relevância e Reforma. In: A Universidade na Encruzilhada. Seminário Universidade: por que e como reformar? Brasília, 6-7 ago. 2003. Brasília: UNESCO Brasil, Ministério da Educação, 2003. 